\title{
The new age of atrial fibrillation: Back to the lab
}

Dawn S. Hui, MD, and Richard Lee, MD, MBA

From the Center for Comprehensive Cardiovascular Care, Saint Louis University, St Louis, Mo.

Disclosures: Authors have nothing to disclose with regard to commercial support.

Received for publication June 9, 2018; revisions received June 9, 2018; accepted for publication June 11, 2018; available ahead of print July 31, 2018.

Address for reprints: Richard Lee, MD, MBA, 3635 Vista Ave, DT 13th Floor, St Louis, MO 63110 (E-mail: rick. lee@health.slu.edu).

J Thorac Cardiovasc Surg 2018;156:1880

$0022-5223 / \$ 36.00$

Copyright (c) 2018 Published by Elsevier Inc. on behalf of The American Association for Thoracic Surgery

https://doi.org/10.1016/j.jtcvs.2018.06.045

Atrial fibrillation (AF) is a clinical diagnosis, and in the contemporary era, clinical treatment of this disease has progressed in a rapid fashion compared with the several centuries over which the disease concept of AF developed. ${ }^{1}$ However, the surgical treatment of AF remains underused and with results that seldom equal those of the gold standard cut-and-sew Maze. A better understanding of the physiologic mechanisms, rather than focusing merely on technologic innovation, may be the key to improving surgical outcomes. In this edition of the Journal, Ruaengsri and colleagues $^{2}$ report on a canine model of chronic left atrial volume overload. By using a controllable left ventriculoatrial shunt, the hemodynamic and electrophysiologic consequences of a simulated chronic mitral regurgitation (MR) were compared with a sham group. This is a major and important step toward addressing a fundamental knowledge gap.

For perspective on the importance of this work, it is helpful to review some selected historical developments in our understanding of AF. As concerns the adage that "AF begets AF," Cox and colleagues ${ }^{3}$ first showed that the perpetuation of AF was sustained through macro-reentrant drivers, leading to the development of the Maze procedure. This preceded Haïssaguerre and colleagues, ${ }^{4}$ discovery that the induction of AF occurs via focal triggers in and around the pulmonary vein orifices. The distinction between these 2 mechanisms is reflected in the ongoing controversies regarding the optimal lesion set for AF ablation. Not all $\mathrm{AF}$ is the same, and the complex and multitude reasons for surgical ablation failure, which may be as high as $20 \%,{ }^{5}$ have been elegantly described by Dr Cox. ${ }^{6}$

Ruaengsri and colleagues'2 work will be important in determining the details of how MR begets AF. In patients with degenerative MR in normal sinus rhythm, the linearized rate of AF development is 5\% annually and associated with increased morbidity and mortality. ${ }^{7}$ Although statistical techniques provide information on associated risk factors, such as age and left atrial dimension, this is no substitute for knowledge of the fundamental processes

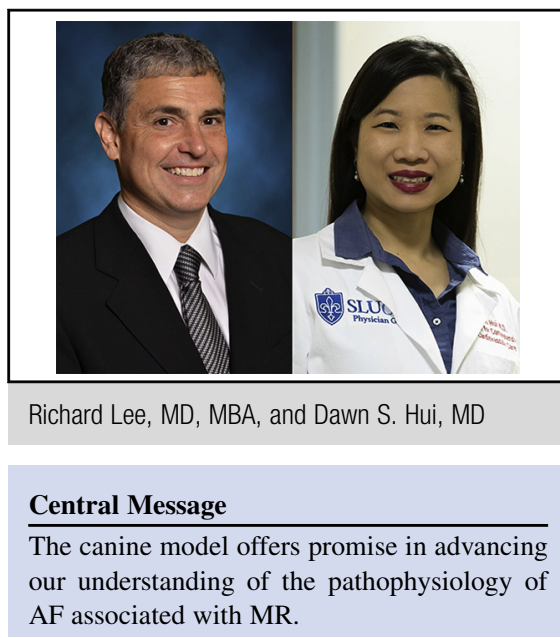

See Article page 1871. that link these 2 disease entities. That said, we note several aspects of the study that may affect its applicability to human physiology. First, the surgical operation simulated immediate MR, which may not mimic the more gradual course that occurs with degenerative disease. Second, the shunt was a nonvalved conduit, creating the potential for bidirectional flow with a vigorous ventricle.

Regardless, it is befitting that the group whose landmark work, not only in foundational knowledge but also surgical innovation and clinical evaluation, may lead us into the future by leading us back into the lab.

\section{References}

1. Flegel KM. From delirium cordis to atrial fibrillation: historical development of a disease concept. Ann Intern Med. 1995;122:867-73.

2. Ruaengsri C, Schill MR, Lancaster TS, Khiabani AJ, Manghelli JL, Carter DI, et al. The hemodynamic and atrial electrophysiologic consequences of chronic left atrial volume overload in a controllable canine model. J Thorac Cardiovasc Surg. 2018;156:1871-9.

3. Cox JL, Canavan TE, Schuessler RB, Cain ME, Lindsay BD, Stone C, et al. The surgical treatment of atrial fibrillation. II. Intraoperative electrophysiologic mapping and description of the electrophysiologic basis of atrial flutter and atrial fibrillation. J Thorac Cardiovasc Surg. 1991;101:406-26.

4. Haïssaguerre M, Jaïs P, Shah DC, Takahashi A, Hocini M, Quiniou G, et al. Spontaneous initiation of atrial fibrillation by ectopic beats originating in the pulmonary veins. N Engl J Med. 1998;339:659-66.

5. McCarthy PM, Kruse J, Shalli S, Ilkhanoff L, Goldberger JJ, Kadish AH, et al. Where does atrial fibrillation surgery fail? Implications for increasing effectiveness of ablation. J Thorac Cardiovasc Surg. 2010;139:860-7.

6. Cox JL. The longstanding, persistent confusion surrounding surgery for atrial fibrillation. J Thorac Cardiovasc Surg. 2010;139:1374-86.

7. Grigionin F, Avierinos JF, Ling LH, Scott CG, Bailey KR, Tajik AJ, et al. Atrial fibrillation complicating the course of degenerative mitral regurgitation. J Am Coll Cardiol. 2002;40:84-92. 